\title{
Introduction
}

Wang Wei (701-61) is one of a very small group of Chinese poets whose fame can be said to be truly international. Along with Li Bo 李白 (701-62), Du Fu 杜甫 (713-70), and Tao Qian 陶潛 (365-427), he defines what Chinese poetry essentially is to readers around the world. Moreover, his verse has come to epitomize in global terms (for better or ill) what a Chinese representation of nature looks like - often a reclusive gentleman sitting in a thatched hut nestled in a mountain nook or a pine grove, playing his zither, reading his books, and observing the beauties of the season pass before him. For many, his poems seem precise visualizations of traditional Chinese landscape painting. No wonder, then, that critics within China and without are quick to connect his verse to his paintings (though few if any of his artworks survive in anything other than copies). And rarely do people fail to quote the prominent literatus Su Shi's 竬軾 (1037-1101) comment on him: "When you savor a poem by Wang Wei, there is a painting within; and when you behold a painting by Wang Wei, there is a poem within." 1 Yet there is a good bit more to Wang Wei than this picturesque quality, even if most selections of his verse tend to downplay his considerable poetic range. This complete translation should help to broaden our vision of who Wang Wei was exactly, and the scope of his talents.

Active during the so-called "High Tang" (roughly the reign of Emperor Xuanzong 玄宗, 712-756), Wang Wei helped define the art of poetry during its cultural high water mark, along with his great contemporaries $\mathrm{Li} \mathrm{Bo}$ and $\mathrm{Du} \mathrm{Fu}$. One could argue that his work was more pervasively influential than that of either $\mathrm{Li}$ or Du: unlike $\mathrm{Li}$, Wang was not an eccentric with a powerful poetic persona stamped on almost every line he wrote; and, unlike Du, Wang was immediately successful while still alive and was widely read from the 730s on. This meant that Wang was perceived as a more imitable model for the poetry of social interaction. For every poet who aspired to the greatness of $\mathrm{Li}$ or $\mathrm{Du}$, there

1 味摩詰之詩。詩中有畫。觀摩詰之畫。畫中有詩。From a painting colophon, “Written on a painting by Wang Wei: “Misty Rain on Lantian”"書摩詰 藍天煙雨. 
were a thousand literati who wanted to write competent poems to commemorate moments of their lives spent with friends or to impress their superiors. Wang Wei helped provide them a template. This can be seen already in the decades after the death of Xuanzong; during the Dali 大曆 era (766-780), poets like Qian Qi 錢起 and Liu Changqing 劉長卿 perfected Wang Wei's regulated verse and turned it into a general style. Jia Dao 賈島 refined it further, giving it some late-Tang tweaks; and with that, the model for mass-produced quatrains and octets of East Asian poetry over the next millennium was created.

This is not to say that Wang Wei's work is bland or mediocre. Critics recognized from the beginning that he was a master poet; and that while the general poetic rhetoric of his work was imitable, he wielded that rhetoric with a skill that was unsurpassed. Most traditional poetic criticism in China occurs in the form of "poetry talks" (shihua 詩話), collections of comments from prominent literati. They have tended to pair Wang Wei with other High Tang contemporaries, usually Meng Haoran 孟浩然 (691-740) and Wei Yingwu 韋應物 (737?-ca. 792), and have attempted to capture his style in distinctive descriptive phrases. They did not always view him uncritically, especially during the Song, but Wang was always one of the touchstones for what High Tang poetry (and poetry in general) was supposed to do. By the Ming, when the preference for High Tang style was largely dictating critical tastes, his place as a canonical master was assured. One trait that continued to make him a source of admiration was his ability to break the tendency of other great Tang poets to favor one particular genre over another; critics acknowledged that he could produce examples of very high quality in every available form: long yuefu ballads, short yuefu quatrains, epigrammatic quatrains, regulated verse poems in seven or five lines, old-style epistle poems, and elegant pailü. Of course, the fact that he could do so also made him a little problematic: he could compose great yuefu comparable with Li Bo's, though still not quite as masterful as his; similarly, his regulated verse could compete with Du Fu's while never surpassing him. And the fact that he was so seemingly chimeric and adaptable perhaps made him a little suspect among those late imperial and modern readers who held self-expression as the most important aspect of poetics.

In more recent times we have seen the gradual development of a sort of conceptual canon of Wang Wei poems that has proved influential 
among modern readers. The outsized impact of the eighteenth-century anthology Three Hundred Tang Poems (Tang shi san bai shou 唐詩三百首) on modern pedagogy helped set that taste: Wang is represented by twenty-nine poems there (in comparison, Li Bo has twenty-seven though many of them quite long - and Du Fu has thirty-six). ${ }^{2}$ Though a dozen or so other poems are often added to this "canon," depending on individual preferences, we have here the Wang Wei verses that most readers educated in the East Asian literary tradition know. This canon has been affected in turn by certain concerns and issues connected to the globalization of literature. The popularity of English romantic-era poetry among twentieth-century Chinese intellectuals helped create the category of "nature poetry" in the Chinese context, and Wang Wei was seen as an exemplar of that cross-cultural genre. Meanwhile in the United States the countercultural tendencies that produced American Buddhism wanted to see Wang Wei as a Zen poet who concealed transcendent wisdom within his imagery. The fact that many of the canonical Wang Wei poems came relatively free of cultural baggage (historical and literary allusions, culture-specific concerns and rhetoric) also helped with this Western popularity, especially among poet-translators. As a result, he is one of the most frequently translated of Chinese poets.

Obtaining a deeper understanding of Wang Wei - one that transcends the impressions provided by the anthology pieces - requires a reading of all 371 poems that can be reliably attributed to him. Hence the advantage of having a complete translation. What do we learn about Wang Wei from doing this? In the comments that follow, I make some suggestions that may prove useful in reading him in a more comprehensive way.

\section{The complete poet}

Much of the scholarship on Wang Wei is focused on relating his poetry to his life; so the first question we might ask is: does reading the com-

2 Here is a list of Wang's poems anthologized in The Three Hundred: 3.5, 3.7, $3.11,3.23,4.7,5.10,6.5,6.7,6.8,7.12,7.16,7.18,7.19,7.23,7.34,8.19$, $8.29,10.1,10.5,10.9,10.14,13.14,13.26,13.31,13.43,14.14,14.19,15.16$, 15.36 (of doubtful attribution). 
plete poems provide a biographical framework for understanding the poet's development and aesthetic preoccupations? Unfortunately, reliable biographical detail is scarce, and the handful of significant moments in his life that are available to us can be summarized briefly. Wang Wei was born in 701, a member of the powerful Wang clan of Taiyuan, though his immediate forbears were only moderately successful office-holders. He soon gained a reputation for precocity and befriended princes of the royal blood while still a teenager. He passed the jinshi examination in 721, and this initiated his official career. Over the course of his life, he held increasingly important (but not major) offices until his death in 761. During those forty years, a number of events stand out:

1. In 721, shortly after earning the jinshi degree, he offended his superiors (for reasons that are not entirely clear) and was exiled to a minor post in Jizhou in Shandong. There he remained until 726.

2. He eventually received the patronage of the chief minister Zhang Jiuling 張九龄; after Zhang fell from power in 737, Wang received the support of Zhang's enemy Li Linfu 李林甫 as well. In 737, Wang was sent as an Investigating Censor to assist the military governor Cui Xiyi 崔希逸 on the northwestern frontier at Liangzhou 涼洲. He returned to the capital of Chang'an after Cui's death the following year.

3. When he was appointed Palace Censor in 740 , he was sent to the south to supervise official selections in the provinces. This resulted in a year of traveling.

4. Sometime in the 740s he acquired an estate at Wangchuan 輞川 (Wang Stream) at Lantian 藍田 in the Zhongnan mountain range south of the capital. The estate provided a rural retreat for the poet, and he probably divided his time between retirement there and his court duties in the capital.

5. When the An Lushan rebellion broke out, Wang Wei was captured by rebel troops in 756 . When Wang faked an illness in order to avoid being pressed into the rebel administration, An Lushan sent him as a prisoner to Luoyang. Eventually Wang took up a post under duress. When he was captured in turn by the loyalists in 757, he was imprisoned once more and threatened with punishment; but the intercession of his younger brother Wang Jin 緇 and the surfacing of two poems he claimed to have written during the 
rebel occupation that suggested his continuing loyalty to the emperor led to his pardon. He resumed official office and was promoted several times before his death, eventually achieving the office of Assistant Director of the Right (右丞 youcheng) in the Department of State Affairs. As a result, he is often referred to in later times as Wang Youcheng.

6. After his death, the emperor Daizong 代宗 (r. 762-779) expressed his admiration for Wang Wei and requested his brother, Wang Jin (then serving as Chief Minister) to submit a copy of his works. Jin told him probably only one of ten poems still survived; he then made inquiries among Wang's friends and associates and compiled the first collection of his work. He submitted it to the emperor, who then deposited it in the imperial library.

These specific events allow for the dating of a certain fraction of Wang Wei's surviving poems. Beyond that, scholars can determine date of composition in many cases through other clues connected to the various offices held by Wang Wei and by the friends and associates mentioned in his verse. Nonetheless, a systematic chronological ordering of Wang Wei's poetry is still largely speculative, and many poems cannot be dated at all. Consequently, we cannot create a coherent "literary biography" of the poet in which life events can help serve as a frame for discussing stylistic developments in the poetry - a strategy that tends to dominate $\mathrm{Du}$ Fu scholarship, for example. But even if we had more biographical detail, it is doubtful that Wang Wei's corpus would permit such a reading. Unlike $\mathrm{Du} \mathrm{Fu}$, Wang Wei spent most of his life as a courtier in the capital, and his verse does not convey the same sense of confession and revelation that is found in Du. In fact, Wang Wei might be termed the last great "medieval" poet of the Chinese tradition. The speaking self in his verse consists of a matrix of social contexts and relationships; who Wang Wei "is" in any particular poem is largely a product of whom he is addressing and the situation in which he is composing. He would not have seen this variability as hypocritical, or as the mere projection of an assumed persona, however: any temporarily held position would be perfectly valid for the moment. This may help explain why he was one of the most versatile poets of the Tang, equally comfortable writing paeans to the emperor, Confucian critiques of policy, celebrations of the rural recluse, descriptions of Daoist Transcen- 
dents, and militaristic frontier ballads. Though evidence suggests that he was most concerned with Buddhist principles (more on this below), he certainly felt no discomfort entering into other modes of life experience. This variety is particularly evident when we read all of the poetry, not just the group of nature poems that tend to attract modern attention and which gives us the illusion of a coherent poetic personality in the modern sense.

In fact, this social aspect needs to be placed at the center of any discussion. When we divide his poetry up by thematic categories, as modern critics often do ("nature poetry," "Buddhist poetry," "court poetry," "reclusion poetry," etc.), we tend to ignore the fact that Wang wrote with an immediate audience in mind and that almost every verse was meant to ornament a social occasion of some sort, from the highly formal to the intimate. He does not use the social moment as an excuse to express himself and his intellectual and aesthetic concerns; rather, he deploys these concerns in ways to ornament the poem and make it more effective as a form of communication that assists in the maintenance of public and private relationships.

The most attractive aspect of this sociality is the way that it commemorates and celebrates friendship. Most famously, there was the poet's close relationship with Pei Di (about whom we know little other than what these shared texts tell us). ${ }^{3}$ But there are many friends in Wang Wei's verse, and when he speaks to these friends, he relies on a wide variety of themes, tropes, and rhetorical devices:

\section{Happy that $\mathrm{Zu}$ Three has come to spend the night}

Before my gate, a guest from Luoyang

Dismounts and brushes off his traveling clothes.

An old friend's carriage does not come in vain,

Though in the course of my life I've often shut my door.

Strollers return to their secluded lanes,

And accumulated snow bears the lingering sunlight.

3 Compositions that reference Pei $\mathrm{Di}$ or are authored by him in this collection: 2.9; 2.28; 7.16; 7.29; 7.31a; 7.32a; 9.5; 10.11; 10.16; 10.16a; 11.24b; 11.24c; $13.1 ; 13.1 \mathrm{a} ; 13.3 ; 13.10-29 ; 13.33 \mathrm{a} ; 13.41 ; 14.17 \mathrm{c} ; 14.26 ; 18.6$. 
You're a bosom friend from our earliest years -

So where else could your lofty carriage find refuge? (7.13)

The Wang Wei touch here is the sensitive, "painterly" evocation of bucolic calm in the third couplet. But it is placed here not out of a desire to portray Nature as such but rather as an evocation of mood, a background to the pleasure of two friends sharing an evening together.

One could write a good bit about the way that shared experiences and comradeship are expressed in Wang Wei's verse - writing as he did to a male elite with an education and career goals in common, he could easily articulate their concerns in a variety of modes. Perhaps one largely ignored mode is humor; there are a substantial number of poems that indulge in gentle satire. In "Presented to an Official from Wu," for example, he sympathizes with (but also teases) an official from southeast China put off by the climate and cuisine of Chang'an:

The Chang'an guest-house is boiling hot

With no tea-infused congee to mitigate the heat.

In vain you wave your white fan - this is the Truth of Suffering;

You wish to take your blue book bag and head back home.

The shipment of salted carp from your river home doesn't arrive;

How could you tolerate the noodle soup of these Qin people?

"I'd rather let myself wander free,

Go shrimping in straw sandals on a Fuchun River islet." (6.17)

To ignore this social aspect of Wang Wei's verse and to treat him as a "serious poet" in the modern sense - an artist struggling to capture the nature of the self and the world in order to fulfill some internalized compulsion - results in a thorough misreading.

The social aspect of Wang's verse also accounts for his taste for sophisticated parallelism that he inherited from the court poetry tradition of the Southern Dynasties and the Early Tang. This dominates not merely his poetry but most of his prose as well (which is written in the highly formal and euphuistic style of the time). Parallelism is perhaps the chief vehicle for wit in medieval Chinese literature, and that is a quality that emerges only when there is a cultivated community available to appreciate it. Though this is a difficult quality to appreciate now (and its beauty is often lost in translation), paying sympathetic 
attention to it has its rewards. For example, in writing of a country excursion with the Prince of Qi early in his writing career, the poet delicately evokes the event:

By the time our enthusiasm is satisfied, the singing birds have changed; As we sit there long, falling blossoms grow many.

The path swerves, makes our silver candles turn back;

The forest opens, dispersing our jade bridle pendants. (7.2.3-6)

The party-goers themselves seem so wrapped in their pleasures that they only notice the passage of time when Nature reminds them (with the transition of birds and the increase of fallen blossoms). As the excursion wends its way back to the city, he imagines a trail of lights as the only indication of the curving country paths; and the change from forest to plain is indicated by a dispersal of the sound of the bridle pendants over a wider space. In both couplets, he subtly suggests that Nature is controlling the event - warning the party-goers when it is time to go home, and laying out the path they have to follow on their way. $\mathrm{He}$ concludes with a surprisingly original couplet, in which raucous entertainers pile up in front of the closed city gates waiting for dawn:

By curfew law the city gates have yet to open;

On the road in front our musicians and singers throng. (7.2.7-8)

The use of elegant parallelism is even more evident in the formal poetry he wrote for imperial occasions. In a poem on the emperor's patronage of the worthy, Wang writes:

He pulls back the tassels from his crown to let his four pupils see keenly;

He leans over the rail, stooping to humble himself thrice to worthies. (11.6.5-6)

Xuanzong, possessed of the sage-emperor Yao's double pupils, releases these keen minister-seeking organs as he brushes aside the crown-tassels of office; and when he sees such worthy men, he abases himself for the sake of his empire, just like Liu Bei, who visited Zhuge Liang three times before the latter agreed to enter his service. Wisdom and humility 
are combined within the parallel structure, hanging together partly through the symmetrical deployment of numbers (four and three). Appreciation of lines like these is an acquired taste, but they display a profound mastery of style.

Other ways in which sociality influences Wang's verse have also been largely ignored. Note, for example, the famous Wang Stream Collection (13.10-19). While these elegant nature quatrains are often held up as the epitome of Wang's interest in capturing the workings of Nature, few critics lay stress on the social context for their production: Wang Wei and his friend Pei Di are wandering Wang's estate, giving names to the most picturesque sites, and exchanging poems that attempt to capture the essential feel of each. It is a combination of tourism, literary gamesmanship, and territorial mapping. ${ }^{4}$ If we ignore this playfulness (and if we read the poems deprived of the matching Pei Di verses), then we miss much of their pleasure, and we end by fetishizing certain of them through decontextualization, as has happened with "Deer Fence" (13.14) or "Lodge in Bamboo" (13.26). For example, we might notice the interactions occurring in two of the lesser-known poems of the collection, 13.22, "Gold-Dust Creek":

\section{Daily drink from Gold-dust Creek}

And at the least you'll live for over a thousand years.

Then on emerald phoenix, with patterned wyverns hovering, With feathered standards you'll come to the Jade Emperor's court.

(Wang Wei)

The eddy trembles and does not flow on,

So that it seems like you could pluck the gold and jade-green.

In the dawn, when it is filled with white blossoms,

I go alone to the task of fetching our morning water. (Pei Di)

We cannot actually be sure which one was written first (we tend to assume that Pei is always responding to Wang, but we have no proof of this). But simply juxtaposing these two quatrains brings out the

4 Ding Xiang Warner (2005) is one of the few scholars who has written about the cycle's social dimensions. 
inherent humor of both. Wang Wei engages in a Daoist fantasy, imagining that the gold-enriched waters can be used for an elixir of immortality that will turn its drinker into a Transcendent; but underlying that second couplet is the common substitution of Daoist tropes for the secular court of Xuanzong, so there is a secondary hint at the continuing thematic tension between service and reclusion - the ideal reclusive activity (becoming a Transcendent) brings the individual back into public service. Pei Di deflates this facetious resplendence by relocating the inhabitant in the modest world of the present and not in the world of future goals and fantasies: he goes to fetch water. The repetition of the word chao/zhao 朝 here accentuates these two opposing views of reclusion in a particularly clever way: "morning" and "attending [morning] court."

Another social aspect that becomes evident on a complete reading is the disproportionate number of "seeing off" poems (usually but not exclusively marked by song 送): out of 371 poems, no fewer than 71 fit this category. 5 These span many different levels of formality - from the yuefu generality and simplicity of 3.23 , to the personal affection of 3.20 and 8.11, to the complex rhetoric of 3.18 and 12.3 (with its lengthy parallel-prose preface). All of Wang Wei's concerns emerge in these poems in one place or another: reclusion, government service, Daoist Transcendents, even Buddhist detachment. But one can detect certain recurring rhetorical strategies as well: historical tourism, for example, in which the poet evokes the famous sites his recipient will encounter on his journey; consolation and sorrow, depending on the reason for separation; and recurring allusions to the biographies of Confucian officials throughout the centuries. To divide this body of verse among certain modern thematic categories and ignore the social occasions that inspired it is to ignore the way the poet could deploy his poetic tools to fit the circumstances - possibly the skill that he himself valued the most as a courtier.

5 This is made more obvious in the Zhao Diancheng edition, which tends to follow the ordering of earlier Ming editions that place all the "seeing off" poems together - see especially juan 3, 4, and 8 . It is difficult to be sure why there should be so many. Perhaps it has something to do with the conditions of the collection's initial compilation by Wang Wei's brother Wang Jin. 


\section{Wang Wei and Buddhism}

The presence of Buddhist ideas and allusions in Wang Wei's work deserves special attention and discussion. Many scholars in China, Japan, and the West have claimed that there is an underlying Buddhist metaphysical perspective in Wang that manifests itself in the way he deploys images (especially nature images). There is also a recurring argument that his poetry shows a serious engagement with the intellectual concerns of the Chan (Zen) movement. Unfortunately, much of this discussion is rooted in two misconceptions.

First, recent scholarship from Buddhologists (John McRae, Bernard Faure, and others) has clarified the state of the Chan movement during the first half of the eighth century. ${ }^{6}$ Later accounts in traditional Chan historiography dating from the Song era tend to portray the Chan movement - especially the more radical "southern" school - as a fully formed manifestation of classic Chan from its earliest days, with its use of paradox, of radical intellectualism, and hostility to ritual and to the religious establishment. But Chan as Wang Wei would have known it was nothing like this; it was still largely defined by a group of monks who placed meditation in the center of their practice and who received court and aristocratic patronage. It was by no means seen as anti-establishment. Wang Wei's mother studied with Puji, a disciple of Shenxiu, who exemplified in many ways this urban and courtly Chan. And though Wang Wei was asked by Shenxiu's opponent Shenhui to write a stele inscription for the so-called founder of Southern Chan, Huineng (25.1), there is nothing in his piece that suggests that he viewed Huineng in the way that the later lineage accounts saw him. It should also be pointed out that later Chan literature, though often formally innovative in its use of the vernacular language and creation of new religious literary genres, usually employed a vocabulary derived from a sutra literature well-known to the educated Chinese believer. It is hardly surprising in such a case that Wang Wei would use philosophical Buddhist terms also employed by Chan texts. If Wang Wei's Buddhist allu-

6 See especially McRae's two books: The Northern School and the Formation of Early Chian Buddhism (University of Hawai'i Press, 1987); and Seeing Through Zen: Encounter, Transformation, and Genealogy in Chinese Chan Buddhism (University of California Press, 2004). 
sions show a fondness for paradox and humor, for example, he is not borrowing this from Chan, but more probably from his favorite Buddhist text, the Vimalakirti Sutra - which derives much of its terminology from the rhetoric on non-duality found in the prajñ äparramitā literature. ${ }^{7}$ The sutra's literary qualities, as well as its central conceit - that a lay believer with a secular life can understand Buddhist enlightenment better than the Buddha's own disciples - would be particularly attractive to the poet as well. But other sutras make their mark on his writing also: in particular, the Lotus Sutra, the Nirvana Sutra, the Pure Land Sutras, and occasionally the Huayan Sutra. These were all texts that an educated believer would be familiar with to a greater or lesser extent. The Wang Wei commentator Chen Tiemin also makes a strong case that Daoguang, whom Wang Wei names as his own teacher in his stele inscription (25.2), was most likely a Huayan practitioner from Wutai (the center of the Huayan movement). I suspect that Wang, like most lay believers, was not terribly interested in sectarian differences. ${ }^{8}$

The second misconception that tends to occur in the literature on Wang Wei and Buddhism is the modern tendency to see Buddhism not as an actual religion with its rituals, devotions, and forms of practice but rather as a sort of psychological affect or as a cluster of philosophical tenets. It is assumed that as a well-read "intellectual," the poet would mainly engage with Buddhism in terms of its ontology, and this would be reflected in subtle ways in his Nature poetry - especially in images that show a preoccupation with emptiness, impermanence, or seemingly epiphanic insights into the cosmos. Unfortunately, this sort of interpretation is largely unprovable. While it is not unlikely that some of these ideas influenced the way that Wang Wei wrote, showing conclusively that he would not have derived the same language and use of imagery from the Chinese poetic tradition as it was practiced in the early eighth century is a difficult task. ${ }^{9}$

7 The importance of this sutra for Wang Wei cannot be underestimated. He chose his polite name (Mojie 摩詰) so that it would combine with his personal name (Wei) to spell out the Chinese rendering of Vimalakirti (Weimojie 維摩詰).

8 The case against Wang Wei's poetry as Chan-influenced is ably made by Yang Jingqing (2007).

9 Owen (1981) and Chou (1982) both tend to see Wang's use of imagery as having roots in a strictly literary tradition. 
There is an irony here that when critics address this issue they tend to ignore the poetry that Wang Wei wrote that explicitly addresses his Buddhist interests. Again, this may reflect modern prejudices: that Buddhism should be psychological and aesthetic, and not doctrinal; and looking at poems where he openly says what he believes, rather than interpreting Buddhist profundity in the movement of a cloud or a stream, may seem unsatisfying. Perhaps even less attractive to many modern critics are the times in which Wang Wei displays his devotion to Buddhist ritual and to traditional forms of piety. ${ }^{10}$ But it is hard to deny that this was a very important aspect of his belief. This is evident enough in poems addressed to monks, or poems visiting temples; but it is most strongly displayed in the prose that he wrote for fellow believers, especially in some of his memorials and eulogies (juan 19 and 20). One might argue that the devotion he expresses in such pieces is merely catering to the tastes of his recipients and does not express his own perspective. But ultimately it is equally likely that he was simply devout, and saw ritual, prayer, and other forms of practice as just as valid as intellectual speculation.

It may also seem a little intimidating when Wang Wei employs Buddhist jargon, and this may explain why critics have preferred to look at the descriptive poems for Buddhist influence, rather than the poems and prose where he is explicitly articulating his Buddhist world view. I have done my best to translate these passages clearly, but I admit that many lines are open to interpretation. However, regardless of their precise meaning, they tend to revolve around the poet's concern with the concept of non-duality and the way it is articulated in prajñäpäramitā texts and in the Vimalakirti Sutra.

In these passages, Wang Wei tends to express his main position in this way: whenever we attempt to understand and express the difference between our world of suffering (samsara) and the realm of enlightenment or absolute reality (nirvana or bhütatathatā), we are doomed to failure, because our language is inherently limited by samsaric values.

10 This probably also influences the desire to see Wang as a Chan poet - since there is an assumption among many modern intellectuals and academics that Chan is rational and opposed to ritual and "superstition" - a position that has been largely debunked by recent Buddhological scholarship. 
Moreover, one of the chief characteristics of samsara that dooms us to suffering is our tendency to think in oppositional categories, and that one such oppositional category is the very placing of samsara and nirvana in opposition. A similar paradox results if we think in terms of the category sunyatā or "emptiness": if we assert that all phenomena are essentially "empty" - that is, that they have no inherent existence in themselves - then we run the risk of creating the conceptual categories of "empty" and "not empty," which would not be valid if we hope to truly comprehend actual, true reality. So "emptiness" is not really "empty" (unless we are thinking of the category "emptiness" that we use to designate it as such in order to talk about it; that really is "empty").

However (and this is important for Wang Wei's role as a poet and as a courtier), we should not give up on language in order to attain some deeper wisdom, because it is a basic tool in the samsaric world. We can use language, not to express adequately the true non-dualistic nature of ultimate reality, but to constantly question and undermine our excessive dependence on duality. If we realize that every time we make an assertion about ultimate reality we must simultaneously acknowledge that assertion's limitations, we are engaged in a fruitful exploration of the problem, even if we can only ultimately experience that reality in a way that transcends language. There is some resemblance here to the via negativa in Christian theology.

Wang Wei uses prajñäpäramitā techniques to make this point, but he also relies on Daoist rhetoric, especially when the Laozi, the Zhuang$z i$, and other texts question the ability of language to express the nature of reality. This can be frustrating to read, because it often means that the poet says (in highly rhetorical and parallelistic fashion) that something is simultaneously true and not-true. However, he can deploy this philosophical insight in ways that have concrete relevance to real-life situations. For example, in 19.10, "Preface to a poem: 'Flowering herbs at the lodging of Master Daoguang at Jianfu Monastery," he begins:

The mind is lodged in the midst of Being and Nonbeing, and the eye is bounded by rüpa [sensuous appearance] on the one hand and Emptiness on the other. All is illusory, and detachment from them is illusory as well. The Fully Realized Person does not cast aside illusion, but he does go beyond the limits of Being and Nonbeing, of rüpa and Emptiness. For that reason his eye may reside 
in the dust while his mind never once shares in that condition. His mind is not in the world, and his body never becomes an object; for identifying oneself as an object causes the Self to be attached through limitless realms, and this is dangerous indeed.

Here we have a typical attempt to undermine dualistic tendencies. The purpose of this rhetoric is more practical, however: he wants to explain why a monk is fond of his herb garden: "His Reverence follows the movements of yin and yang, and acts in company with the passions. At the twin tree's place of practice he turns all the flowers into a form of Buddhist activity."

Analysis of non-duality is perhaps most important for the poet when he uses it to resolve the ever-present tension between government service and retirement - which had a long history in Chinese philosophy and literature, and was a major preoccupation of his own. In 3.14 he provides a meal for monks of a local monastery, then argues that he does not need to withdraw from public service to practice:

Already awakened to the joy of Stillness, I have more than enough leisure for this life. A desire to retire - why must it be serious? For both self and world are truly empty.

He makes this argument in a much more detailed way in his "Letter to Layman Wei" (18.7) - introducing a general critique of Chinese reclusion in the process:

A lofty one of old said, "Xu You hung his gourd from a tree; but because the wind blew through it, he disliked it and tossed it aside. When he heard that Yao had abdicated, he came to the river and washed out his ears." But the ears are not the place to block sounds, nor do sounds have traces that stain the ear; rather, if one despises things on the outside, one is polluted within; and a dislike for external things springs up from within the Self. Someone like this cannot attain the status of a truly open-hearted man. How is this truly entering the gate of the Buddhist path? And when it came to $\mathrm{Xi}$ Kang, he as well has said, "When a deer is captured, it will toss its head wildly to throw off its bonds, and will long more and more 
for its tall forest trees and will pine for its lush grasses." "Tossing its head wildly to throw off its bonds" - how is that any different from lowering one's head and accepting the restrictions of office? "Tall forest trees and lush grasses" - how is that any different from the gates leading to government office? When discriminating views arise, then the true nature is obscured; when sensuous phenomena intervene, then our ability to apply wisdom weakens. How could this be a viewpoint that allows for the sole existence of a vision that sees all things as equally empty, so that emptiness pervades all things and brings illumination to all? This is also something that you know.

In other words, from a non-dualistic perspective, being a hermit is the same as being in office - an ideal position to take for a devout courtier and an admirer of Vimalakirti.

\section{Recurring clusters of allusions}

In the translations that follow, I have attempted to footnote allusions to the extent that it makes the poems comprehensible - it would take too much space to explore every way in which Wang echoes or plays with the phrasing of an old text or is engaged in dialogue with the literary past. However, it may help the reader here to make some generalizations about what texts and what historical references occur most often, beyond the Buddhist concerns mentioned above.

Textual allusions: Though Wang was probably familiar with the full range of Chinese literature up to his own time, he tends to allude to the same small group of texts over and over again. Most evident are allusions to The Analects, the Zuo zhuan, the Shijing, and the Zhuangzi. The Yijing and the Liezi show up occasionally as well, but not nearly as often.

Historical allusions: these tend to fall into four general categories:

1) Han era topography and administration: Tang era palaces, institutions, bureaucratic titles and (often) place names are replaced with their Han equivalents. This perhaps should not even be termed allusion; it is more a form of elegant substitution. In particular, the use of Han era palace names is meant to glorify the Tang court by 
comparing it (especially) to the reign of Emperor Wu. Very little Confucian criticism of Emperor Wu's excesses is ever suggested.

2) The Xiongnu wars: any frontier poetry inevitably alludes to the history of conflict with the Xiongnu during the Western Han, especially during the reign of Emperor Wu. The great generals of the time (Huo Qubing, Wei Qing, Li Ling, Li Guangli, etc.) are regularly evoked. The degree to which the foreign policy conflicts of Xuanzong's reign are being seen through the lenses of a distant and idealized past (though common enough in Tang verse) is quite striking.

3) Eastern Jin and Southern dynasties eccentrics: Not surprisingly, Wang draws on the anecdotal literature of this period (usually found in the Shishuo xinyu): Xie An, Wang Xizhi, Shi Chong, Huiyuan, and others are mentioned fairly often.

4) Tales of Daoist Transcendents: While Wang deploys the technical language of the Daoist faith, he leans toward the anecdotal when addressing poems to Daoist friends and acquaintances. This suggests that he is sympathetic to Daoism and broadly familiar with it, but not at the level of an initiate.

\section{Conventions of translation and editions}

Some translation conventions: Daoist xian 仙 are translated as "Transcendents." The Yangtze is translated as "the Jiang." When poem titles refer to the recipient's age rank within his extended family, this is rendered as a cardinal number rather than an ordinal one (e.g., "Zu Yong Three"). Official titles are translated for the most part using Charles O. Hucker, A Dictionary of Official Titles in Imperial China (Stanford University Press, 1985).

The edition translated follows the basic order and text of the Zhao Diancheng 趙殿成 edition of 1733 . This is by far the best known. It follows the structure of Ming editions in organizing the poems by metrical genre. In this case, Juan 1 consists of "old style verse" of irregular and 4-syllable lines; Juan 2-5 consist of old-style verse in five-syllable lines; juan 6 consists of old-style verse in seven-syllable lines; juan 7-9 consist of five-syllable regulated octets; juan 10 consists of seven-syllable regulated octets; juan 11-12 consist of five-syllable pailü; juan 13 consists of five-syllable quatrains; juan 14 consists of six-syllable and seven- 
syllable quatrains; and juan 15 consists of a supplement of poems of doubtful provenance. There is a tendency to group poems by occasional subgenre within these groups (e.g., all the parting poems are placed together). The prose collection is also arranged by genre. There is no attempt to order things chronologically (not surprising, since the majority of Wang's poems and much of the prose cannot be dated with certainty).

Zhao decided to include all of the poems available to him that had been attributed to Wang Wei, even if he himself was convinced that they were not by him. I have decided to be completist as well and translate all of them, noting when evidence suggests a different author. Poems likely misattributed by Zhao that are not in juan 15 include: 3.22 ; 4.14-15; 4.24; 8.8; 12.8. The most striking example of misattribution is the group of thirty poems likely composed by Wang Ya that have been included in many (but not all) early editions; their inclusion seems to stem originally from Guo Maoqian's attribution of them to Wang Wei in the Yuefu shi ji.

Zhao also includes matching or answering poems by other poets, and I have translated most of those as well, since I believe that seeing the compositional context of a poem when possible increases our understanding; this is especially true of the famous Wang Stream Collection, where the inclusion of the Pei Di poems is essential. The only exceptions are a number of "blue sparrow" poems (6.3) and some long imitations of Wang by Chu Guangxi (to 5.4-5.9 and 5.20) that Zhao has included, but which I find insufficiently engaged with the Wang Wei texts to warrant their translation.

In selecting what prose to translate I have tried to pick the pieces a modern reader would find most interesting. I have tended to favor those with Buddhist content, since this gives us a better context for understanding the poet's engagement with the faith in its entirety. Even in his letters Wang tends to write in a florid style with frequent use of parallelism. I was tempted to translate all of the prose as verse, but I decided eventually that that would detract from the narrative coherence of each piece.

Readers should also take note that one of his best prose pieces, the preface bidding farewell to Abe no Nakamaro, is here placed with the poem it prefaces and not with the prose (12.3). 
I have reluctantly decided not to translate the discourse on landscape (Shanshui lun), in spite of its fame: scholars have known for a very long time that it is not by Wang Wei, and it deserves the attention of an art historian. Besides, we already have an excellent translation of it by Susan Bush and Hsiao-yen Shih. ${ }^{11}$

As with the works any great Tang poet, Wang Wei's collection has a large variety of variant readings, and I have included the important ones in a section at the end. ${ }^{12}$ Not surprisingly, the poems that were famous from early on often have the widest variety of variants. The amount of variation within the textual lines of the Wang Wei collection itself is fairly reasonable, but there is a good bit of difference when the collection text is collated with the early compendia (Wenyuan yinghua, Yuefu shiji, Tang wen cui, etc.). I have largely kept to the Zhao edition, but have often accepted the practical emendations suggested by Chen Tiemin (1997). The Quan Tang shi text also has a surprising number of unique variants, suggesting that its editors relied on earlier editions of the collection no longer extant.

11 Early Chinese Texts on Painting (Cambridge: Harvard University Press, 1985), 173-76.

12 To prevent too large a selection, I have only included actual surviving edition variants. I have omitted variants listed as such in pre-modern editions that do not cite a source (usually marked only by yi zuo 一作). 
